\title{
VIVO PARA PENSAR PELÍCULAS. ENTREVISTA (ANOTADA) A FERNANDO COLOMO
}

\author{
Débora Madrid Brito \\ Universidad Autónoma Madrid
}

\section{RESUMEN}

La obra cinematográfica de Fernando Colomo es ampliamente conocida. Se trata de uno de los cineastas españoles fundamentales del periodo de la Transición española. Sus primeros largometrajes dieron lugar a la designación de la llamada «nueva comedia madrileña» y su prolífica actividad ha dejado, a lo largo de las décadas, numerosas películas, guiones, producciones e interpretaciones. El presente trabajo se propone, a partir de una entrevista realizada al director a comienzos de 2017 , contextualizar y comentar sus principales aportaciones, contribuyendo así a aumentar la escasa atención académica que, hasta ahora, se le ha prestado al cineasta.

Palabras Clave: Fernando Colomo, cine español, nueva comedia madrileña, entrevista.

\section{LIVE TO THINK MOVIES. (ANNOTATED)}

INTERVIEW WITH FERNANDO COLOMO

\section{Abstract}

Fernando Colomo's cinematic works are well known. He is one of the principal filmmakers of the period of Spain's transition to democracy. The first films of the director gave rise to the label of «New Madrid comedies» and his fruitful work has resulted in numerous films, scripts, productions and performances. This publication seeks, through the interview done with Fernando Colomo at the beginning of 2017, to contextualize and discuss his main achievements. Hence, this present paper aims to shed light on the significant contributions of this film director, whose works have received little attention in academia.

Keywords: Fernando Colomo, Spanish film, new Madrid comedy, interview. 
Fernando Colomo (1946-) es una de las figuras más representativas del cine español de la década de 1980. Se formó en arquitectura mientras devoraba revistas cinematográficas y desgastaba las butacas de los cines, y estrenó su primer largometraje-Tigres de papel-en 1977. Sus primeras películas dieron pie a la denominación de lo que se conoció como la "comedia madrileña», historias que, tanto a nivel argumental como a nivel formal, representaron un soplo de aire fresco en la cinematografía española, en una época en la que todo lo que sonase a espontáneo, novedoso y alejado de normas preestablecidas era bien acogido. Ejerciendo una intensa actividad como director, productor, guionista y actor, Colomo no ha dejado de trabajar a lo largo de las décadas y actualmente prepara su nuevo largometraje, La tribu, que espera estrenar en 2018. A lo largo de la presente entrevista, que no pretende recoger un desarrollo estricto de su filmografía desde el punto de vista cronológico, emanarán diversas cuestiones que han marcado la carrera del director: desde sus referentes iniciales y sus motivaciones para dedicarse a la dirección cinematográfica, el cuestionamiento de esa etiqueta que la crítica acabó imponiéndole de "padre de la comedia madrileña", el inagotable debate entre la concepción del cine como una propuesta autoral y las motivaciones comerciales e industriales, las carencias del cine español del periodo (como la falta de guionistas formados o las dificultades de la distribución internacional), la eterna comparación o competición con el cine americano, la polémica del doblaje, etc.

Acompañaremos las reflexiones y comentarios de Fernando Colomo con anotaciones a pie de página que pretenden contextualizar o profundizar en algunas de las ideas planteadas, aderezando así la entrevista con aportaciones propias que enriquezcan y complementen los escasos estudios previos ${ }^{1}$ existentes sobre la figura del director madrileño y su obra cinematográfica. Nos recibe Colomo en febrero de 2017, en una cafetería del barrio madrileńo de Chamberí, donde reside actualmente.

- ¿Cuáles son sus referentes cinematográficos?

Fernando Colomo: El cine me viene directamente de Truffaut, concretamente de Los 400 golpes $^{2}$, que la vi en el cinefórum del colegio con quince años y fue un

\footnotetext{
${ }^{1}$ Hasta donde hemos podido comprobar, el único libro monográfico publicado sobre la figura de Fernando Colomo es El efecto Colomo, publicado en 1998. Desde entonces, se ha podido constatar un cierto interés académico en el director por la realización de diversas tesis doctorales: Carty, Gabrielle M. (2002): Female Roles in the Comedy Films of Fernando Colomo, tesis doctoral defendida en el Queen Mary and Westfield College, University of London; Lara Martínez, María (2011): Fernando Colomo, tesis doctoral dirigida por Luis Fernando Huertas Jiménez, Universidad Complutense de Madrid, Departamento de Comunicación Audiovisual y Publicidad; e Iglesias García, Paula (2015): La representación del cambio social en el cine de la Transición: la comedia madrileña, tesis doctoral dirigida por Juan Carlos Ibánez en la Universidad Carlos III de Madrid, Departamento de Periodismo y Comunicación Audiovisual.

${ }^{2}$ Les 400 coups (François Truffaut, 1959). La película, como muchas del cine francés de esos ańos (las de los cineastas de la Nouvelle Vague o la Rive Gauche), fue muy influyente para el mundo cinematográfico de la década de 1960; fue considerada en la prensa española como «uno de
} 
flechazo para mí. En aquella época estaba muy de moda Antonioni, porque Los 400 golpes ya era una película antigua ${ }^{3}$, nosotros la vimos después. Y algunas de Godard ya habían también pasado. Pero Antonioni estaba en plena vigencia, estrenaba en el cine Avenida de la Gran Vía El eclipse, y me influyó mucho eso, que curiosamente es lo más opuesto a mi cine ahora mismo, ahora me entra la risa, pero al principio fue así. Dentro de la Nouvelle Vague primero Truffaut, un poco más tarde me dio también muy fuerte con Godard y Rohmer. Luego quizás mis películas se parecieran más a las de Rohmer, por el planteamiento, incluso la última, Isla bonita, tiene un planteamiento un poco de Rohmer, en el sentido de que utilizo también actores no profesionales e improviso con ellos.

- ¿Su pretensión ha sido entonces la de traer de alguna manera a España ese cine que se estaba haciendo, sobre todo en Francia, y responder a los planteamientos provenientes de la teoría de autor?

F.C.: Yo quería hacer un cine que no se había hecho en España, que era hacer cine con personajes reales, lo cual no se había hecho sobre todo por la censura, salvo brillantísimas excepciones como El verdugo, El pisito, Calle Mayor ${ }^{4}$ o alguna película que conseguía más o menos burlar la censura ${ }^{5}$, pero que eran muy pocas. La cuestión es que no podías contar historias de la gente, no podías utilizar un lenguaje cotidiano. Yo recuerdo, por ejemplo, con Tigres de papel, que los distribuidores me decían que los tacos a las personas mayores no les gustaban, decían que en el cine no debían decirse tacos. Pero era un lenguaje coloquial que se hablaba en la calle ${ }^{6}$. Recuerdo que un señor

los [filmes] más importantes de cuantos recientemente hemos visto» (La Vanguardia, 25/12/1959). En España Fernando Colomo se hizo eco de este cine francés a finales de los 70, proponiendo un cine espontáneo y natural, tanto desde el punto de vista de los temas, guiones y diálogos como desde el apartado visual, el bajo presupuesto, la improvisación y el trabajo con actores no profesionales.

${ }^{3}$ Los 400 golpes se estrena originalmente en junio del año 1959 en Francia, y en marzo de 1961 en Madrid (ABCMadrid 1-5/03/1961). Si Fernando Colomo, nacido en 1946, recuerda tener 15 o 16 ańos cuando la vio por primera vez puede que la viera el mismo año de 1961; por lo que cuando Colomo dice que se trata de una película antigua es probable que se refiera a que ya no estaba en cartelera cuando él pudo verla en el cineclub.

${ }_{4}^{4}$ El verdugo (Berlanga, 1963), El pisito (Marco Ferreri, 1959), Calle Mayor (Juan Antonio Bardem, 1956).

${ }^{5}$ La censura cinematográfica impuesta por la Administración franquista se mantuvo en Espańa hasta dos años después del fallecimiento de Franco (aunque con menos restricciones ya en los últimos momentos). Fue precisamente ese ańo, 1977, cuando Fernando Colomo estrenó su primer largometraje, Tigres de papel.

${ }^{6}$ "Nos gustaría insistir en ese carácter de cronista social y anteponerlo al tan manido encasillamiento de Colomo como "rey de la comedia" y más concretamente de la llamada "comedia madrileña". Etiqueta poco definida que da una visión parcial de la filmografía del cineasta». Montero, Pablo y Utrilla, David (1998): El efecto Colomo, XXIV Festival de Cine Iberoamericano de Huelva, p. 11. 
me dijo en un coloquio que en las películas americanas no se decían tacos, y yo le recordé que estaba viéndolas dobladas... Entonces eso era lo que yo quería hacer. Además, veía que era un cine barato e incluso heredero del neorrealismo, pero ya más cerca. El neorrealismo era como mis abuelos, y la Nouvelle Vague, como mis padres, ${ }^{7}$ y tuve la suerte de ser el primero en España que lo empezó a hacer. Cuando hice Tigres de papel, todavía no se había hecho ninguna película toda en sonido directo ${ }^{8}$ y con una serie de personajes que hablaran tanto. Además, que los personajes hablaran mucho hacía que las películas pudieran ser más baratas. Esta primera película se rodó en tres semanas y media, cuando lo mínimo para una película barata eran unas cuatro semanas y para una película ya un poco más gorda se necesitaban unas siete u ocho.

- Se le suele describir como un gran autor de comedia ${ }^{9}$, pero ¿¿cuál es su relación con la comedia? ¿Fue su intención desde el principio hacer comedias?

F.C.: Nunca pensé hacer comedia. Para mí fue una sorpresa. Desde Tigres de papel empezaron a decir que era una película con tono de comedia, luego ya pasó a ser una comedia directamente. El año pasado se proyectó en Tarragona en un festival ${ }^{10}$ en el que se pasó Isla bonita y Tigres de papel, mi última y mi primera película, porque Isla bonita se decía que recuperaba el espíritu de mis primeras obras. Y luego en el coloquio, una de las señoras que estaba allí me dijo que era una película muy deprimente, muy triste, que los personajes y el niño, pobrecitos. Y lo que dije fue eso, que realmente no era una comedia. ¿Dónde está la comedia?

7 En consecuencia, el estilo visual de Colomo destacará por la austeridad y la sencillez, donde la cámara trata de pasar desapercibida para dejar el protagonismo a los personajes. Así, según avanza su carrera la steady-cam se convertirá en una gran aliada para el director, junto al montaje transparente, una iluminación austera y una narración lineal.

${ }^{8}$ Es frecuente remarcar a Fernando Colomo como uno de los precursores del uso del sonido directo en el cine español, en una época en la que el doblaje era una práctica constante impuesta durante el franquismo.

9 En las historias generales del cine español se sitúa constantemente la obra de Fernando Colomo en el capítulo de la comedia, como ocurre, por ejemplo, en Castro de Paz, José Luis, PÉrez Perucha, Julio y Zunzunegui, Santos (2005): La nueva memoria. Historia(s) del cine español (1939-2000), A Coruña, Vía Láctea Editorial; donde se describen películas como La vida alegre y El efecto mariposa (1996): como "comedias de enredo" con "ciertos ecos de la actualidad política» (pp. 284-285). Otra manera de calificar sus primeras películas (Tigres de papel o ¿Qué hace una chica como tú en un sitio como este?, 1978) ha sido en contraposición a las comedias de Berlanga de los años 70 y describiéndolas como «un tipo de comedia generacional y desenvuelta que poco tenía que ver con el cine de autor al uso». Gubern, Román, Monterde, José Enrique, Pérez Perucha, Julio, Rimbau, Esteve y Torreiro, Casimiro (1997): Historia del cine español, Madrid, Cátedra. Signo e imagen, p. 396.

${ }_{10}$ Fue en la Xvi edición del Festival Internacional de Cinema de Tarragona, que se celebró del 30 de noviembre al 6 de diciembre de 2016. 
- Sin embargo, le calificaron como el padre de la «comedia madrileña».

F.C.: Sí. Lo primero es que la comedia madrileńa yo siempre dije que yo no sabía lo que era. En realidad, es un topónimo, esto de "madrileña» ${ }^{11}$, pero a Woody Allen nadie le dice que hace comedia neoyorquina, ni a Eric Rohmer que es la comedia parisina.

- Quizá tiene que ver con esa idea de hacer en España un cine que antes no se había hecho y que se empezaba a hacer desde Madrid.

F.C.: Sí, además hubo alguna otra película también que era, por así decirlo, del mismo palo, porque, contra todo lo imaginable, Tigres de papel fue bastante comercial; eso hizo que otros productores decidieran hacer películas similares, que, además, como era muy austera y muy barata, con muchos diálogos, pues era muy fácil. Entonces hubo varias, entre ellas alguna que produje yo como Ópera prima ${ }^{12}$ (que luego de alguna forma superó todo eso porque fue la película más comercial del año 1980). Pero ya antes de Ópera prima se hablaba de la «nueva comedia costumbrista madrileña», ese era el título completo. Luego, al cabo de tres años, pues ya había que quitar lo de «nueva», $y$ "costumbrista" debe ser que era una palabra un poco larga y tampoco se entendía por parte de la gente y entonces se quedó como la "comedia madrileña» ${ }^{13}$.

11 «El hecho de que sus primeras películas transcurran casi en su totalidad en Madrid tiene más que ver con un motivo de falta de presupuesto que de estilo consciente». Montero y UtriLla, (1999): El efecto Colomo, Huesca, Festival de Cine de Huesca, p. 18. De hecho, gran parte de sus películas posteriores están rodadas fuera de Madrid, incluso alguna de su primera época, como $\mathrm{La}$ línea del cielo (Nueva York, 1983). En total Colomo ha filmado hasta en siete países distintos, desde Estados Unidos hasta Marruecos: El caballero del dragón, 1985, Girona; Miss Caribe, 1988, México y Florida; Bajarse al moro, 1989, Marruecos; Alegre ma non troppo, 1994, Santander; El efecto mariposa, 1995, Londres; Los años bárbaros, 1998, Francia; Cuarteto de La Habana, 1999, Cuba; Al sur de Granada, 2003, Granada; La banda Picasso, 2012 en París; Isla Bonita, 2015, Baleares.

12 Dirigida por Fernando Trueba y estrenada en 1980.

${ }^{13}$ Esta definición categórica ha sido recientemente estudiada en profundidad por Paula Iglesias García. La autora aborda la llamada comedia madrileña y se cuestiona si esta debe considerarse como un "subgénero» o "fenómeno" de otro tipo, reconociendo, al mismo tiempo, que no existe un discurso consensuado acerca de las características que lo definen. Su propuesta concluye con una redefinición de dicho fenómeno como «nueva comedia sentimental», eliminando la referencia toponímica a Madrid, y entendiendo este conjunto de películas «como reacción a una determinada manera de concebir la producción comercial de comedias que venía desarrollándose desde finales de los años sesenta y principios de los setenta. Se trataba de construir un territorio fundamentalmente diferente a aquel en el que se había establecido la comedia del llamado cine de la tercera vía»; y centrándose en cómo estas películas hacen «circular una serie de valores y visiones del mundo que hablan de los cambios que operan en España en el tiempo de la transición a la democracia». IgLEsias, op. cit. pp. 18 y 7. 
- Y esta etiqueta que le viene desde fuera ¿dónde surge?, ¿viene de la crítica?

F.C.: Sí, yo creo que nace en un festival de San Sebastián, donde decían: viene una película checoslovaca, otra francesa, dos americanas y dos comedias madrileñas.

-¿Y por qué no dos comedias españolas?

F.C.: En aquel momento se decía que era muy de Madrid la forma de hablar de los personajes. Y yo decía: «Pero bueno, hablan como hablan los actores, jes que tengo que quitarles el acento?». Incluso me lo decían como demérito. Recuerdo que un amigo mío vasco me lo decía: «Es que tiene todo ese lenguaje madrileño» y yo dije: "Bueno y si tú haces una película en vasco, ¿está mal o qué?».

- Era un momento quizás muy sensible en cuanto al tema de las identidades regionales.

F.C.: Claro, Madrid seguía siendo el centro y se seguía viendo con un poco de rechazo.

- Entonces, más que la comedia parece, revisando su filmografía, que lo que realmente le interesa son las relaciones personales. Es lo que más se repite. ¿A qué se debe esto?

F.C.: Sí, por ejemplo, Tigres de papel se me ocurrió antes del guion, y claro, el que se te ocurra una película antes que el guion es como un cierto parto, porque no sabes de qué o por qué vas a hacer una película. Recuerdo que la película se basó en la pareja de Carmen Maura y Joaquín Hinojosa, que yo los conocía. Estamos hablando del año 1976 cuando la escribo, 1977 cuando la ruedo. Y ellos tenían una relación muy buena a pesar de estar separados y tener un hijo, ella iba los domingos a verle a él para que estuvieran los dos con el niño y esto me sorprendió, porque no era lo habitual. Luego el referente era Bergman, concretamente, Secretos de un matrimoni ${ }^{14}$, que era una película muy de hablar. Y yo pensé: puedo hacer eso, pero contando estas cosas que yo conocía. Entonces les dije que quería hacer una película basada en ellos. De hecho, los personajes se llaman Juan y Carmen y el niño se llamaba Iván, y Miguel Arribas hizo de mí, luego fue casi el protagonista, el personaje que más sesiones tenía. Pero si te das cuenta es una película como de fines de semana. Y es que yo iba un fin de semana y estaba allí con ellos y entonces pues aparecía un día la vecina, etc., y yo iba viendo como ese microcosmos. Y estuve yendo un par de meses y luego me puse a escribir y tenía mucho material, muchísimos

14 Scener ur ett äktenskap (Ingmar Bergman, 1973). 
diálogos, personajes, situaciones, y a partir de ahí lo fui encauzando. Otra película que me influyó a la hora de ver la estructura es una que se llama $B o b$ \& Carol \& Ted \& Alice, que la vimos en España en los años setenta, pero era anterior ${ }^{15}$. Eran cuatro personajes que se intercambiaban, eran dos parejas y de pronto se liaban unos con otros. Yo fui a verla y recuerdo que cuando salí, mentalmente apunté todas las secuencias, eran catorce secuencias temporales: la presentación de estos, la presentación de los otros, el encuentro, etc., y me di cuenta de que utilizaba una estructura. Porque a mí en aquella época nadie me había hablado de guion, ni de la estructura de tres actos, todo esto de lo que ahora hay muchísimos libros, pues antes no había nada. Entonces me sirvió un poco para pensar en hacer algo parecido. La película no se parecía, nunca copiaba contenidos, pero copiaba las estructuras.

- En cuanto a lo que comenta de crear el guion, ha mencionado en alguna ocasión ${ }^{16}$ el problema de la falta de guionistas profesionales en el cine español.

F.C.: Sí, siempre lo he dicho, que el gran problema del cine español son los guiones. Y esto afecta totalmente a la calidad de las películas. Ahora mismo, el guionista es el que está peor pagado de la industria, salvando excepciones, que ya han muerto, como Azcona (que sí pedía lo que se merecía). Pero normalmente a los guionistas se les regatea mucho, sobre todo ocurre que si ya has escrito el guion nunca te lo van a pagar, porque como ya está escrito..., ya te pagaremos si se hace la película.

- Quizá por esa idea proveniente de la gran influencia que tuvo en España la teoría de autor y que el director escribiera los guiones de sus propias películas, se ha desprestigiado la figura del guionista.

F.C.: Eso también, y fíjate que estoy tirando piedras sobre mi propio tejado. ${ }^{17}$ Por supuesto, está bien que los directores escriban sus propios guiones. Pero claro, que todos escriban sus propios guiones empieza a ser un poco problemático.

${ }^{15}$ Bob \& Carol \& Ted \& Alice (Paul Mazursky, 1969). Estuvo en cartelera en los meses de febrero y marzo de 1977 ( $A B C$ Madrid 25/02/1977 y 12/03/1977).

16 «Es el gran drama del cine español. A lo mejor es porque los españoles tenemos una gran tradición visual y somos muy buenos en pintura y en cómic. En la época de Berlanga había escritores de teatro como Mihura incorporados al cine. Pero en mi generación ya entramos directamente en el cine de autor, y esto a la larga tiene un efecto negativo, porque supone la desaparición de la figura del guionista. En España al guión se le sigue despreciando. Se desprecia hacer guiones con plantillas. Parece que todo se puede aprender menos el guión. Que te llega de las musas. Y no, el guionista necesita una formación y el guión tiene una técnica [...]. En España tenemos técnicos cojonudos, pero seguimos sin guionistas y sin buenos guiones. Y para mí es mucho más duro escribir un guión que fotografiar una película». Fernando Colomo en Montero y Utrilla, 1998, op. cit. pp. 42-43.

${ }_{17}$ Colomo ha sido el guionista de todas sus películas; de hecho, el cineasta figura con una entrada propia en el diccionario de guionistas del cine espańol: Rimbau y Torreiro, Casimiro (1998): 
- Acaba por no existir un sector de guionistas al que acudir o del que aprender.

F.C.: Claro, porque además no había ninguna escuela. Aprendíamos hablando de películas, decíamos: «Esta es como tal película» y a veces ni nos acordábamos muy bien de cómo era, porque tampoco podíamos acudir al guion de aquella película, recordábamos momentos. Por ejemplo, películas como $E l$ apartamento $^{18}$, que era una obra maestra, sobre todo en la parte de guion, pues sí, las estudiábamos, pero te resultaba difícil salir de ahí.

- Y cuando ha trabajado en colaboración con otros guionistas ¿̨ha notado la diferencia?

F.C.: Sí, a veces para peor. Aunque en general siempre he tratado de trabajar con guionistas, aunque algunas, por circunstancias las he hecho yo solo. Pero lo ideal es que puedas tener a alguien que te haga un poco de frontón y que te ayude a organizar y te diga lo que ve o lo que no ve. Escribir un guion es complicadísimo, tienes que tener muy bien los personajes, durante hora y media o dos horas no puedes aburrir, así que tienes que tener esto que decía Mamet de que la estructura dramática consiste en que cada escena lleve a la siguiente, que el espectador diga ¿qué va a pasar ahora? En el momento en que no pasa eso el espectador desenchufa. Y la construcción de los personajes requiere también documentación, es trabajo de calle, lo ideal es incluso a veces grabar a la gente, te vas acostumbrando a escuchar. Como decía Juan José Millás, si un guionista o un escritor sale a por tabaco y no vuelve con una historia, no es escritor. Siempre coges algo, yo cuando voy en el autobús, sobre todo con la gente joven intento pegar la oreja, ver cómo hablan, qué expresiones utilizan, y ya es algo que hago inconscientemente.

- Volviendo un poco al tema de sus películas, se repiten las relaciones amorosas poco convencionales, de amantes con casados, parejas divorciadas que se mezclan, o relaciones que no llegan a realizarse.

F.C.: Claro, es que cuando hice mi primera película, en 1977, era la primera vez que podías hablar de algo que no te habían dejado hablar antes. Había habido

Guionistas en el cine español. Quimeras picarescas y pluriempleo, Madrid, Cátedra y Filmoteca Española, pp. 223-224. Aunque también ha trabajado para muchas de ellas con otros guionistas como Olivia Delcán (Isla bonita, 2015), Inés París (Rivales, 2008), Joaquín Oristrell (Rivales, El próximo oriente, 2006; El efecto mariposa, 1996; Allegre ma non troppo, 1994 y Bajarse al moro, 1989), Miriam Ruiz y Jonathan Gathorne-Hardy (Al sur de Granada, 2003), Julio Carrillo (El Cuarteto de La Habana, 1999), Carlos López y José Ángel Esteban (Eso, 1997 y Los años bárbaros, 1998), Ana Klamburg (El efecto mariposa), Miguel Ángel Nieto (El caballero del dragón, 1985), Andreu Martín (El caballero del dragón; Estoy en crisis, 1982)...

${ }_{18}$ The Apartment (Billy Wilder, 1960). 
películas como Muerte de un ciclista ${ }^{19}$ o El verdugo, pero eran personajes no reconocibles, yo no me identificaba con el verdugo, que era de una clase social diferente a la mía. Y yo de pronto dije: «Voy a contar lo que yo sé». Eso también lo había oído de la Nouvelle Vague, cuando a ellos les preguntaban que por qué no hablaban de la guerra de Argelia, y ellos decían que no querían hablar de lo que no conocían.

- Es decir, que hay algo de experiencia personal en las películas que hace.

F.C.: Sí, en general las experiencias personales es lo que te da un plus. Yo tengo tal deformación que ya no sé si vivo para escribir guiones o pensar películas, entonces de pronto digo: «Voy a meterme en este lío a ver qué pasa, a ver si aquí hay alguna historia». Y esto es algo natural, porque cuando las historias no parten de ti no son originales y sin darte cuenta estás contando cosas que han podido contar quinientas personas antes.

- Siempre tiene que haber algo de verdad en las películas.

F.C.: Lo ideal, en cualquier creador, es que hagas algo que solamente puedas hacer tú. No que tomes algo que te gusta y lo hagas a la manera de fulanito, cambiando algo, eso no sirve para nada. Lo que pasa es que el cine es tan complicado y tan caro que todo lo que sea tener un sello personal no es fácil de conseguir porque hay muchos intereses y en el momento en que hay otros productores te empiezan a imponer actores, y entonces ya se va yendo de la idea que tú tienes.

- ¿Ha dejado de contar cosas que quería contar debido a este tipo de presiones o por satisfacer al público?

F.C.: Yo lo que siempre pienso es que si hay una cosa que te interesa a ti, le puede interesar al público, si se lo sabes contar, de una manera abierta u original. Aunque con esto luego te llevas muchos chascos, puedes pensar que una película va a ser buenísima y luego la ves y dices «qué horror», o todo lo contrario, crees que una película no va a ser muy interesante en su resultado final y luego la ves y dices "qué película ha salido». Es muy aleatorio el cine, es lo bonito que tiene, que nunca sabes lo que te vas a encontrar.

19 Muerte de un ciclista (Juan Antonio Bardem, 1955). 
- ¿Se considera un cineasta «de autor», o cree que esta categoría y su separación con el cine de género ya están superadas? ${ }^{20}$

F.C.: Lo que pasa es que lo de cine de autor tiene una carga demasiado fuerte. Yo considero que todos somos autores de una manera o de otra. No creo que haya un gran cine de autor por un lado y un cine comercial por otro. Bueno, sí que lo hay, se ve muy claro en los presupuestos, por ejemplo. Pero en España nos pasa una cosa curiosa y es que, si tú aquí intentas hacer cine comercial, puede que luego no resulte nada comercial y que luego sea más comercial una película de autor, rara, porque ha obtenido premios. Los géneros son algo relativamente reciente en el cine español, salvo el caso de la comedia. En el género policíaco se habían hecho cosas interesantes en Barcelona, por ejemplo, como Distrito quinto o Un vaso de Whisky ${ }^{21}$, pero nunca acababa de cuajar. Sin embargo, en los últimos años, el cine policíaco o el thriller se han convertido en un cine que es comercial, pero al mismo tiempo los críticos lo reconocen como de calidad, cosa que con la comedia no pasa. Si tienes una comedia de mucho éxito, con suerte te perdonan la vida.

- Por tanto, sí que sigue funcionando esa diferenciación en cuanto a la calidad de una película en función de si tiene un discurso más personal.

F.C.: Claro, aunque el cine de género quienes lo reivindicaron históricamente fueron los de la Nouvelle Vague. Aunque ellos hacían un cine, como Los 400 golpes, que era una película muy personal, o Al final de la escapada ${ }^{22}$; el cine que a ellos les gustaba era el Hitchcock, Howard Hawks, John Ford, Otto Preminger y Jerry Lewis. Godard decía que Jerry Lewis era un genio. Entonces, eso es chocante, porque ellos reivindicaron el cine americano como cine de autor. Lo que reivindicaron precisamente es que el autor no tiene que serlo solamente si es guionista y cuenta una cosa muy personal, sino que también está en películas como Hatari, una de las últimas de Hawks, de 1962, que era de safaris, con un reparto muy internacional; y yo recuerdo que Godard decía que Howard Hawks había conseguido hacer lo que Antonioni ha estado intentando hacer toda su vida.

${ }^{20}$ En el cine español, y especialmente en el sector de la crítica cinematográfica, las categorías de cine de autor o cine de géneros siguen operando, a pesar de que «la política de subvenciones estatales, orientada desde 1994 en mayor grado a los rendimientos en taquilla, y reforzada por el gobierno del Partido Popular (1996-2004), pone en entredicho la dicotomía entre un cine artístico de autor para élites académicas, y un cine "de encargo" y distracción para las grandes salas. Los representantes de la joven generación de los noventa del siglo xx aceptan la dimensión económica del cine como un reto, no como una contradicción al estatus del autor, lo cual no impide que el cine español actual y sus críticos sigan rindiendo un culto al auteur». Pohl, Burkhard y Türschmann, Jörg (eds.) (2007): Miradas Glocales. Cine español en el cambio de milenio, Madrid, Iberoamericana-Vervuet, p. 17.

${ }^{21}$ Ambas dirigidas por Julio Coll en 1957 y 1958, respectivamente.

22 À bout de soufflé (Jean-Luc Godard, 1960). 
- Digamos que ellos supieron reconocer dentro de la industria americana, es decir, dentro de un cine comercial, determinados elementos que hacían que las películas pudieran ser consideradas como productos más personales e incluso artísticos.

F.C.: Exactamente. Aunque ellos, a su vez, no hicieran ese cine, entre otras cosas porque ese cine solamente lo pueden hacer los americanos, por todo, por los actores, por las localizaciones, por las historias, etc. Pero todo esto que estoy diciendo está en contradicción con lo que hemos visto en Espańa o incluso en Francia. Por ejemplo, en Francia el polar, como lo llaman ellos, el policíaco, tiene mucha aceptación o la novela negra en el caso de la literatura.

- ¿Considera que es importante la influencia de la literatura? ¿Cree que, por ejemplo, si hubiera existido un mayor desarrollo en España de la literatura de ciencia ficción ${ }^{23}$, hubiéramos producido más cine de ese género?

F.C.: El problema que tienen las películas de ciencia ficción es que son caras, porque tienen muchos efectos y si las haces con poco dinero te quedan cutres. $E l$ caballero del dragón es el primer intento de hacerlo con gran presupuesto, pero aun así nos quedamos cortos, porque yo tenía una idea de presupuestos de películas pequeñas; entonces, aunque lo multiplicase por ocho, seguía siendo pequeño. Y es una película que tampoco tuve mucho tiempo para rodar. Los efectos estaban más planificados y la película la rodamos durante ocho semanas, que era como lo máximo en aquel momento, y luego otras ocho semanas con equipo reducido para los efectos especiales y otros detalles, trabajo de laboratorio, mucho trabajo de posproducción. Este tipo de películas, si no tienes un gran presupuesto, te quedas corto.

- El problema siempre es la debilidad de la industria espańola.

F.C.: Por eso al final siempre vuelves a hacer Nouvelle Vague, porque es muy barato. Mi última película, Isla bonita, no es tan barata como La línea del cielo, pero casi, con un equipo de seis personas, no había personal de maquillaje, ni vestuario, ni script, ni producción ni nada.

${ }^{23}$ Para un repaso histórico por la literatura del género de ciencia ficción en España desde sus antecedentes en el siglo Xvir ver SaInz Cidoncha, Carlos (1976): Historia de la ciencia ficción en España, Organización Sala Editorial; para un acercamiento más reciente DíEz, Julián y Moreno, Fernando A. (2014): Historia y antología de la ciencia ficción española, Madrid, Cátedra, Letras populares. 
- En pocas ocasiones le gusta hablar sobre El caballero del dragón $n^{24}$, una película que llama mucho la atención dentro de su filmografía.

F.C.: Lo que pasa es que a El caballero del dragón le tengo mucha manía, más que nada porque me arruinó, o más que me arruinó, me endeudó. Tuve la suerte de que, con la siguiente película, La vida alegre, que la hice milagrosamente, conseguí pagar todas las deudas.

- ¿Cómo surgió la idea de la película? ¿Es cierto que la inspiración parte de un grabado o alguna otra imagen que vio en alguna revista?

F.C.: El caballero del dragón, desgraciadamente, se me ocurre a mí. Hay varias inspiraciones. La primera fue viendo un documental en el festival de San Sebastián, que era como de la prehistoria y aparecían unos símbolos como de posibles visitas de extraterrestres. Entonces se me ocurrió que, realmente, siempre contamos las historias de extraterrestres en nuestra época actual, como si llegaran ahora, y realmente para un viaje interestelar 500 años es una tontería. Entonces la idea era que llegara un extraterrestre a la prehistoria. Pero luego vi una imagen que esa ya me inspiró más concretamente, que era como un cómic y mostraba de espaldas en primer término a un astronauta, de los primeros que fueron a la luna, con la mochila muy aparatosa y al fondo se veía un castillo al estilo Walt Disney, el típico de princesa medieval. Y se veía una princesa corriendo hacia él por un camino. Me pareció una cosa muy curiosa, poder mezclar la Edad Media con extraterrestres, y a partir de ahí se empieza a disparar todo.

- ¿Y cómo entra en esta historia el personaje de san Jorge?

F.C.: Yo escribo el guion en Barcelona, porque le había propuesto el proyecto a Andreu Martín, y yo creo que es allí donde surge la idea de san Jorge. Pasé allí unos tres meses trabajando en el guion y juntos empezamos a hacer bocetos. Empecé a trabajar con gente del mundo del cómic, la pareja Ventura y Nieto. Enrique Ventura es un dibujante buenísimo y comenzó enseguida a hacer bocetos porque queríamos tener la idea de la película de un modo muy visual y Miguel Ángel Nieto era otro de los guionistas. La idea era la llegada de una nave extraterrestre y al llegar ha quemado las cosechas y la población cree que es un dragón que echa fuego por la boca. Entonces recuerdo que Enrique

${ }^{24}$ A pesar de que la entrevista no pretende profundizar película a película, hemos considerado relevante extendernos en el caso concreto de El caballero del dragón, puesto que se trata de una de las películas más insólitas dentro de la filmografía del cineasta y una de las menos estudiadas. Además, fue, según la prensa, la película de mayor presupuesto del cine español hasta ese momento (La Vanguardia, 19/12/1985 p. 57) y aborda uno de los géneros menos conocidos de la cinematografía nacional, el de la ciencia ficción. 
dijo que si llegasen unos extraterrestres con una tecnología tan avanzada no necesitarían quemar el campo para aterrizar. Y ahí empezamos a cambiar cosas. Tanto Ventura como Nieto eran muy fans de la ciencia ficción e insistían en que no cayéramos en fallos en los que habían caído otras películas, como las que habían querido representar por ejemplo cruce de naves en el espacio a una velocidad superlenta, porque se tenía la imagen de la película de Kubrick. Yo hacía el story-board con Enrique, aunque no lo conservo, porque con el paso del tiempo fui eliminando cosas y desgraciadamente no tengo nada de ese material ${ }^{25}$. Yo era quien hacía un primer borrador y luego Enrique lo dibujaba bien. Yo también dibujo, pero él es un maestro, es un tío que tiene mucha mano, pintaba caballos con una facilidad tremenda, yo hubiera tardado mucho más y él le daba un acabado muy profesional. No todo el guion fue dibujado, pero sí un $40 \%$ aproximadamente, sobre todo las secuencias en las que había algún efecto. Luego Ventura hizo unas diez láminas en tamaño grande de determinados momentos de la película y eran unas ilustraciones espectaculares: el extraterrestre con la lanza, un caballero medieval, etc., y esas imágenes nos sirvieron (siempre digo que desgraciadamente) para que nos dieran dinero por muchos lados. La verdad es que fue un atrevimiento decir, desde Barcelona, que sant Jordi era un extraterrestre. Aunque en realidad no es un santo de santoral, es una leyenda, con lo cual encajaba bien en la historia. Cada vez que veía en Barcelona algunos grabados de los que hay allí, no sé si por el barrio gótico en la fachada de la Diputación o del Ayuntamiento hay un escudo en el que están sant Jordi y el dragón y la verdad es que me atraía muchísimo.

- En la prensa se asoció mucho durante su rodaje y el momento del estreno con otras películas del género ${ }^{26}$, ¿ocurrió esto conscientemente con intención de promocionar la película como una película de efectos especiales que atrajera al público joven?

F.C.: Realmente la película llamó mucho la atención porque era la de mayor presupuesto del cine español hasta entonces, había tenido la máxima subvención y yo tenía todos los ojos encima, con todo el mundo esperando a que cometiera un error para lanzarse sobre mí. Eso fue una gran tensión que tenía todo el tiempo. Había esa expectativa, de una película en España con efectos especiales, ya que de las de ciencia ficción que se habían hecho en España esta era la que tenía más presupuesto. Por tanto, la intención que se tenía era que

${ }_{25}$ Sin embargo, algunos dibujos del story-board de la película han sido reproducidos en el libro de Montero y Utrilla (1998), op. cit.

${ }^{26}$ Había grandes expectativas, por ejemplo, con el diseño de la nave espacial, de la cual llegó a decirse que «es un diseño barroco que es algo así como un cruce entre Alien y La guerra de las galaxias, sin ser ninguno de los dos» (Fotogramas, n. ${ }^{\circ} 1714$, diciembre 1985, pp. 54-57). 
la película fuera muy sonada, que se hablara de ella, independientemente de que se tratara de asemejar al género o no.

- ¿Se trató, quizá, de una estrategia comercial el hacer una película de género (junto al rodaje en inglés o el reparto internacional)?

F.C.: Es cierto que era completamente distinta a las películas que había hecho, sobre todo a la inmediatamente anterior, La línea del cielo, que es la que he hecho con menos presupuesto. La había rodado en Nueva York y de pronto te planteas que quizás puedes intentar hacer algo diferente, que quizás puedas llegar a otros públicos, sobre todo porque La línea del cielo había sido muy improvisada. Me apetecía entonces hacer una película en la que todo estuviera diseñado, que cada fotograma estuviera dibujado y muy pensado. Y rodar en inglés era obligado para poder tener una distribución exterior y para poder traer actores internacionales, claro.

- ¿Qué otras referencias a la cultura o la sociedad española se trató de incorporar en la película? El papel de la mujer o de la Iglesia, por ejemplo (con respecto al contexto español de los ańos ochenta). Es decir, ¿de qué manera se relaciona esta película con el resto de su filmografía?

F.C.: Sí, eso ya nacía desde el guion. Con Andreu, que es bastante iconoclasta, enseguida surgían este tipo de referencias. Era el poder del nigromante, del alquimista, frente al poder de la Iglesia, ese enfrentamiento. Dentro de ese reino de la princesa, intentábamos darles la vuelta a cosas, efectivamente él era el bello durmiente y ella la que al darle el beso le despertaba. Aunque ese comentario social que mencionas surge de manera casi involuntaria, pero, por otro lado, es lógico, en una película en la que además de productor y director eres guionista, pues vas añadiendo detalles; así que, aunque aparentemente era una historia muy lejana, surgen esos detalles propios del momento.

- ¿Tiene la película alguna relación directa con el Quijote? Me ha parecido que hay alguna referencia explícita, como cuando el caballero de la guardia real lucha contra la nave como si luchara contra los molinos.

F.C.: Sí, más concretamente a un grabado de Doré. Cuando Harvey Keitel estaba velando las armas, le enseñamos un grabado de Doré en el que aparece Don Quijote velando el yelmo y la bacinilla, que los tenía sobre unas piedras ${ }^{27}$.

${ }^{27}$ El grabado pertenece a la serie de Gustave Doré que ilustra una versión de Don Quijote de la Mancha, concretamente de la parte I, capítulo III. Puede consultarse en la Biblioteca Virtual Miguel de Cervantes: http://www.cervantesvirtual.com/portales/miguel_de_cervantes/imagenes_quijote_dore/imagen/imagenes_quijote_dore_03_cervantes_quijote_dore/ [fecha de consulta 14 de diciembre de 2017, 17: 14]. 
Lo de la lucha del caballero contra la nave, como Quijote contra los molinos, es cierto, también tenía eso, aunque ahora que lo dices, no sé si fue algo voluntario o involuntario. Pero sí que mezclamos muchas cosas.

- ¿Qué repercusión tuvo la película? No solo a nivel económico, que fue escasa en comparación a la inversión, sino a nivel social. ¿Recuerda alguna crítica especial que le llamara la atención, algún comentario de algún espectador...?

F.C.: No, en general la gente se quedaba muy sorprendida. Influyó mucho a la gente que el personaje extraterrestre lo hiciera Miguel Bosée ${ }^{28}$; creo que en el caso de Espańa esto influyó negativamente, porque la gente no se creía a Miguel Bosé haciendo de extraterrestre. Pero para mí era el actor perfecto porque tenía el físico que nos gustaba. No lo trajimos porque vendiera más, realmente estuvimos meses buscando extraterrestres y era muy complicado.

- Quizá tiene que ver con el hecho de que cuando los espectadores se enfrentan a una película de ciencia ficción les echa para atrás encontrar elementos demasiado reconocibles, como era el caso de Miguel Bosé, que les hacían quizá creer menos en la película.

F.C.: Exactamente. Yo creo que eso fue un poco negativo. A la gente la parecía poco serio que él hiciera de extraterrestre.

- Volviendo un poco al resto de su filmografía, generalmente trata temas más cotidianos, de vivencias más personales que va recogiendo. ¿Condiciona eso que las películas sean menos exportables o sí que ha podido distribuirlas en el exterior?

F.C.: El problema con lo exportable fuera es que, por ejemplo, en general, la comedia, lo mismo que el vino, viaja mal. Eso siempre lo han dicho. Es decir, que tú haces una comedia en Francia, como Intocable ${ }^{29}$, que la vieron 20 millones de personas en Francia y, esa misma, se trae a España y aunque es un gran éxito no hace ni la décima parte de lo que ha hecho en Francia. Bienvenidos al sur ${ }^{30}$ fue también un gran éxito, y pasó lo mismo. Pero claro, en este caso la gracia era que se trataba de una región determinada. Lo que se hizo fue

${ }^{28}$ Originariamente, el papel principal se pensaba que sería interpretado por Imanol Arias, pero el hecho de que el personaje no tuviera diálogos hizo que rechazase el papel, optando entonces Colomo por Miguel Bosé (El Periódico de Catalunya, 30/11/1985 p. 35). Otras fuentes son más ambiguas afirmando que la cancelación del contrato se debió a que Arias consideraba que "este año debía hacer otro tipo de personaje» (Diario 16, 21/07/1985 pp. 36-37).

${ }_{29}$ Intouchables (Olivier Nakache y Eric Toledano, 2011).

30 Benvenuti al sud (Luca Miniero, 2010). 
copiar la misma fórmula, y Ocho apellidos vascos ${ }^{31}$ viene de ahí. En definitiva, lo que quiero decir es que la comedia parece que es menos universal, está más ligada a las costumbres del país. Sin embargo, el drama parece que es más internacional y siempre se ha tomado más en serio y además puede ir asociado a premios; siempre estamos otra vez en lo mismo.

- Bueno, pero si quedamos en que sus películas son comedia solo en ocasiones y por casualidad, no tendrían este problema a la hora de viajar fuera.

F.C.: Bueno, algunas sí que viajaron. La línea del cielo, porque estaba rodada en Nueva York y tuvo una buena crítica, fue a un festival allí, New Directors, New Films, y tuvo una crítica fantástica en el New York Times ${ }^{32}$, la pusieron por las nubes y entonces la vendimos. El precio fue pequeñito, pero sí tuvo una presencia. Pero esa es la única que he conseguido estrenar en Estados Unidos. El caballero del dragón creo que se ha puesto en vídeo y creo que tuvo mucho éxito en ambientes gais, porque salía Miguel Bosé depilado y muy guapo.

- Precisamente La línea del cielo refleja un poco ese complejo español frente a lo que se hace fuera. ¿Fue esa la intención de esta película?

F.C.: Lo cierto es que quizás es la película más biográfica dentro de mi filmografía, porque todos los personajes eran mis amigos, al único que sustituí fue a mí por Antonio Resines; de hecho, los americanos le llamaban el alter ego. Entonces en la película repetía conversaciones reales que había tenido en mi experiencia allí, mis amigos repetían conversaciones que habíamos tenido, pero con Antonio. Fue una película impulso, no es que estuviera dándole vueltas a la idea de hacer una película sobre el tema de un español que viaja y demás, sino que te ves allí y de pronto te ves mal, no tienes un duro, todo

31 Ocho apellidos vascos (Emilio Martínez-Lázaro, 2014).

32 «... a witty, low-keyed Spanish comedy, written and directed by Fernando Colomo, [...]. The film will be shown at the 57th Street Playhouse tomorrow in the "New Directors/New Films" [...]. Nothing of great moment happens to Gustavo during his visit, but Mr. Colomo discovers comedy everywhere. [...] Skyline is a slight but endearing comedy that, like Gustavo, regards New York with a mixture of wonder, amusement, open-mindedness and skepticism. Mr. Resines is a very droll Gustavo, a fellow who never loses his cool, partly because, being a tourist in a mysterious land, he doesn't want to be impolite and because, at heart, he has realized that for him it will never be more than a nice place to visit. Mr. Colomo never forces the comic events or overstresses the ironies. The movie possesses a charm that, though gentle, is firmly rooted in the realities of a completely self-absorbed civilization». (Vicent Canby, New York Times, 3 de abril de 1984). Otras de las positivas críticas que tuvo la película en Estados Unidos ese mismo ańo pueden verse en: Box Office (diciembre), L.A. Weekly (7 de septiembre) The Hollywood Reporter (16 de agosto) Los Angeles Times (7 de septiembre), Village Voice (31 de julio) y Los Angeles Herald Examiner (7 de septiembre). Todas ellas de 1984 y disponibles en la Margaret Herrick Library, Academy of Motion Picture Arts and Science, Beverly Hills, California. 
te está saliendo mal, etc., y sobre todo porque el idioma era un bloqueo brutal, y de pronto dices: "Aquí hay una película». Yo en realidad me estaba documentando para un guion para otra película, la razón por la que yo voy es porque escribía un guion con Trueba, que era la historia de un artista inspirado en Tàpies y en teoría en un hecho real. Decían que Tàpies pintó un cuadro y que lo había comprado un multimillonario americano muy importante, y el cuadro empezó a deshacerse, porque Tàpies trabaja con arenas, etc. Entonces lo llamaron para que restaurara el cuadro y Tápies se negó porque entendía que la obra era así, se supone entonces que aparecieron unos agentes americanos que se lo llevaron a Tápies a Chicago a punta de pistola. Esto debe ser una leyenda, me lo contaron en Cuenca en el museo de arte abstracto, pero no se me ocurrió preguntarle a Tàpies. Pensábamos hacer esta película con Fernando Fernán Gómez, el artista en este caso era escultor, llamado, en lugar de Tàpies, Parets, y le raptaban dentro de su propia obra, hacia como unos huevos gigantes. Nunca se llegó a hacer porque cuando yo contaba esto allí en Nueva York se quedaban aterrorizados con la historia, no entendían para qué quería hacer esta película, porque era como una serie de clichés, del artista, que estaba enamorado de una bailarina, el gánster, etc. Entonces pensé que era verdad y esto me iba hundiendo más, pero a los quince días, visitando el Actors Studio, vi un cartelito con una frase de Elia Kazan que decía algo así como que el artista o el actor debe utilizar sus propias frustraciones como forma creativa. Entonces dije: «Yo en quince días tengo ya una colección de frustraciones que si las pongo en orden esto es una película». Así que me puse a rodar la película sin saber cómo terminaría y por supuesto sin guion, tenía solo tres folios escritos a lápiz. Vino Antonio Resines, vino el director de fotografía, que era Ángel Luis Fernández, vino Antonio Isasi hijo, que me hacía de ayudante de producción porque era el único que hablaba inglés.

- Partiendo un poco de ese intento siempre de rodar fuera, o distribuir fuera las películas, ¿cómo valora el cine español y a los directores españoles en relación con la competición internacional, sobre todo el cine americano?

F.C.: Se ha producido en los últimos años un hecho que antes no pasaba, que era que determinadas películas, las que están producidas por las cadenas privadas, son promocionadas como si fueran películas americanas, con el mismo tipo de lanzamiento, de machacar con la publicidad, etc. Entonces lo que se ha descubierto es que funcionan y dan tanto dinero como las del cine americano o más quizá, incluso siendo más baratas. Vamos, que la promoción es muy importante, porque hoy en día vivimos en una sociedad completamente llena de estímulos visuales. Antes, por ejemplo, estrenabas una película y te daban dos, tres o cuatro semanas de crédito y si veían que la película iba subiendo, la dejaban. Por ejemplo, en el caso de Ópera prima, en la que fui productor, la estrenamos y a las dos semanas la querían quitar; tuvimos que meter más publicidad y en solo diez días empezó a cambiar, 
empezó a funcionar el boca a boca y de estar a punto de quitárnosla pasó a estar casi un año en el cine Paz, un cine de muchísimas butacas, y se llenaba los fines de semana. Fue un fenómeno, la más comercial del año con 14 copias, cuando ahora se hacen por encima de 500 copias. Era otro tipo de distribución, las copias se movían mucho y no se requería un lanzamiento $\tan$ fuerte de entrada. Sin embargo, ahora, si no tienes un lanzamiento fuerte, por dinero, o porque la película gana premios en algún festival o algo, pues no aguanta ni una semana.

- Es decir, que todos esos esfuerzos que en ocasiones se han hecho de rodar las películas en inglés, de traer actores internacionales, etc., apenas sirven si no hay una buena promoción detrás. Se trata entonces de conseguir que el público se entere de que esa película existe y así acuda a las salas desde el estreno.

F.C.: Totalmente; además, hoy en día es terrible, se estrenan cada semana doce o quince películas, no lo sé, pero son muchísimas, cuando antes eran alrededor de cinco y tenías siempre la oportunidad de tener una repercusión. Ahora mismo, a lo sumo, algún crítico te hace una reseña y poco más. Piensa en cines como los cines Princesa; yo, por ejemplo, con Alegre ma non troppo estuve ahí seis meses, y, sin embargo, con Isla bonita estuve una semana al $100 \%$ y otra con la mitad de proyecciones que la primera. Actualmente no hay tiempo para que el boca a boca funcione. Las películas duran el tiempo que tienen los cines para reorganizarse y quitarlas, se estrenan los viernes y algunas si pudieran las quitaban desde el sábado.

- En su última película reflexiona mucho sobre el mundo del arte, más allá del cine, ¡esto es algo que desde siempre le ha interesado?

F.C.: Siempre tuve mucha facilidad para el dibujo, así que con catorce años empecé a estudiar un curso por correspondencia que era de historietas. Yo lo que quería era hacer cómics, era muy fan de los dibujantes españoles, era capaz de distinguirlos a unos de otros por sus dibujos e incluso descubría cuando a veces copiaban a los americanos. Tenía mucha memoria visual y recuerdo haber visto una viñeta de Flash Gordon, que me encantaba, cogiendo de perfil a un extraterrestre con una expresión muy fuerte en la cara y de pronto me encuentro en unos tebeos de Jesús Blasco exactamente la misma escena, era en este caso de indios, pero con la misma expresión. Entonces sentía como que yo entendía de aquello, que sabía si un dibujante era bueno o malo. En aquella época aprendí mucho de dibujo, de perspectiva y todo eso en el curso por correspondencia, y ganaba muchos concursos en el colegio. De hecho, vivía de eso, de todos los concursos que se organizaban, por el día de la Inmaculada, por el día del Seminario, todos estos premios de dibujo que se hacían para promocionar estas festividades. Así que me gustaba mucho dibujar; de hecho, luego estudié arquitectura, no porque quisiera estudiar arquitectura realmente, sino porque con 17 años que terminaba el colegio en 
aquella época, pues entrabas en la universidad. La escuela de cine, que solo había una en España y era muy selectiva, con solo ocho plazas por especialidad, estaba concebida como una escuela de posgraduados, y para entrar tenías que tener 21 años. Con lo cual, yo no tenía ninguna coartada para decirle a mi padre que quería hacer cine; mientras tenía que hacer algo. Al principio quería hacer bellas artes, pero tuvimos muchas discusiones porque decían que estudiando bellas artes iba a ser un don nadie. Yo quería hacer bellas artes y al mismo tiempo quería seguir viendo cine y aprendiendo mucho de cine. La idea era dedicarme al cine y que bellas artes fuera casi como un complemento o una base, y al final acabé haciendo eso con arquitectura, que fue un poco más duro, claro, porque no era fácil.

-¿¿Ha seguido dibujando?

F.C.: Trabajé luego de arquitecto, fui arquitecto municipal del pueblo de mi padre, que era Villa del Prado, aquí en la provincia de Madrid, a unos 60 kilómetros. Al mismo tiempo conseguí ir haciendo cortos con el dinero que ganaba como arquitecto, así que fui ahorrando y haciendo cortos hasta que hice mi primera película con la ayuda de otros arquitectos amigos que aportaban pequeñas cantidades. Así hice una pequeña sociedad, que se llamaba la Salamandra, con la que hice mis primeras películas, hasta El caballero del dragón. Más tarde pasé de practicar el dibujo a la pintura. Siempre me había gustado la idea de pintar al óleo, pero nunca tuve dinero, ni tiempo, ni espacio. Es una técnica complicada y me apunté a unas clases que daba una pintora, Carmela Santamaría, que impartía clases a cinco o seis en su estudio, éramos un grupo de dos jubilados, una azafata, un adolescente y yo. Estuve dos años o año y medio y aprendí la técnica del óleo, a partir de ahí hice alguna exposición, una de ellas en la galería Kreisler, en el año $2009^{33}$.

- ¿Considera el cine como una más entre las artes, o es algo ajeno, más relacionado con la industria del ocio?

F.C.: Tiene las dos cosas, el espectro del cine es muy amplio. Por un lado, es una forma de expresión creativa y, por otro, evidentemente, una industria potentísima,

33 En el catálogo de la exposición se describe así su obra pictórica: «La pintura de Colomo, sorprendentemente desconocida hasta el momento, debería figurar en todas las historias de la sombra. Cabría pensar de esta afirmación que sus obras resultan oscuras o lóbregas, pero son increíblemente luminosas. Diríamos que es un pintor paradójico, pues nos cuenta cada cosa desde su contraria. Quizá también por eso, aunque su técnica no guarda relación alguna con el hiperrealismo, las escenas que retrata poseen la calidad de real que tenemos usted y yo y los objetos de que nos rodeamos. De ahí también la dificultad para ser espectador de sus cuadros: al medio minuto de observarlos, como me ocurre a mí en el que tengo en casa, estamos dentro de ellos. Nos convertimos en el cuadro y nuestro cuerpo en un reflejo de él». Millás, Juan José (2009): Fernando Colomo, Madrid, Galería de Arte Kreisler, p. 3. 
que se lleva muchísimo dinero, especialmente la industria americana. Además, aquí en España está el problema de que les hemos regalado el doblaje, les hemos regalado nuestro idioma, y no pagan nada por ello.

- ¿Qué opina del doblaje?, ¡es algo que no tiene vuelta atrás?

F.C.: Sí, claro que tendría, lo que pasa es que tiene que haber una voluntad política, pero parece ser que Felipe González lo intentó y duró medio asalto la idea, porque hay una industria alrededor del doblaje. Pero bueno, también hay industria armamentística, quiero decir que, aunque afecte eliminarlo, es un mal menor. Hay actores muy buenos de doblaje, pero que posiblemente si no hubiera doblaje estarían haciendo películas.

- Es curioso cómo aquí doblamos las películas al castellano y, al mismo tiempo, rodamos en inglés para poder distribuir.

F.C.: Claro, porque en Estados Unidos no nos dejan distribuirlas en nuestro idioma. Allí no hay ninguna legislación, simplemente hay mafias. Allí no se usa el doblaje al inglés, el público desde niño está acostumbrado a que todo es con sonido directo, y la proyección con subtítulos reduce el espectro de público que va a ver las películas. Es el caso de Almodóvar, que se vende en Estados Unidos, y dentro de los cines en versión original seguro que sus películas son de las que más venden, pero no es ni una pequeña parte de lo que podría hacer si esa película se doblara al inglés y nadie dijera nada. Pero allí ante la más mínima des-sincronía, el público entiende que se le está engañando y no pueden entender que un actor no aparezca con su propia voz. Y eso es lo que ocurre también aquí, por eso si las películas americanas se proyectaran en España con subtítulos, el cine español haría más dinero, iría menos gente a ver el cine extranjero, y los que irían, aprenderían además inglés.

- Ahora con el éxito de las series de televisión y la distribución a través de internet sí que se consume mucho la versión original; sin embargo, cuando el público acude a las salas no va tanto a las versiones originales.

F.C.: Esto es porque en la sala de al lado tienen la película doblada, y la mayoría de la gente se queja de que no va al cine a leer, que hay que estar pendiente de las letras, pero es porque no lo han hecho desde pequeños, el público no está acostumbrado. Los niños son listísimos, aprenden muy rápido y les costaría mucho menos. En Portugal, por ejemplo, que no tienen tan desarrollado el doblaje, por falta de dinero, pues las ponen subtituladas, qué suerte. 